\title{
O EGITO NA INTERFACE ENTRE O DIÁRIO DE DOM PEDRO II E OS JORNAIS “DIÁRIO DE MARANHÃO" E "DIÁRIO DO RIO DE JANEIRO" EM 1876 E 1877
}

\author{
EGYPT IN INTERFACE BETUEEN DIARY OF DOM \\ PEDRO II AND THE NEUSPAPERS “DIÁRIO DE \\ MARANHÃO" AND “DIÁRIO DO RIO DE JANEIRO" IN \\ 1876 AND 1877
}

\author{
Maced Talaat Mohamed Ahmed Elgebaly' \\ LIIIANE FARIA CORREA PINTO²
}

Resumo: Este artigo analisa a história do imaginário do Egito e a técnica da "escrita de si" no "Diário de Dom Pedro II" na sua viagem a esse país entre 1876 e 1877, em interface com os jornais "Diário do Maranhão" e "Diário do Rio de Janeiro" na mesma época. As notícias dos jornais foram analisadas, colocando essas informações jornalísticas em diálogo com a textura literária e memorialista do "Diário de Dom Pedro II", a partir do "mapeamento" dos lugares afetivos percorridos pelo monarca no seu "Diário".

Palavras-chave: D. Pedro II, Egito, imprensa.

Abstract: This article analyzes the history of the imaginary of Egypt and the technique of "writing the self" in "Diary of Don Pedro II" in his travel to that country between 1876 and 1877, in interface with the newspapers "Diário de Maranhão" and "Diário do Rio de Janeiro" at the same time. News stories were analyzed, putting this journalistic information with literary \& memorialistic texture of "Diary of Don Pedro II", by mapping the affective places of "Dom Pedro de Alcântara" in the Diary.

Keywords: D. Pedro II, Egypt, press.

1 Professor Coordenador do Departamento de Língua Portuguesa da Aswan University.

2 Professora Adjunta e Coordenadora da Curso de Licenciatura em História a Universidade Federal do Maranhão, Campus VII, Codó - MA. 


\section{Introdução}

Em 1871, Dom Pedro II (1825-1891) visita o Egito e escreve o seu primeiro diário sobre esse país entre os dias 3 e 14 de novembro de 1871. Em 1876, Dom Pedro II retorna e escreve o segundo diário entre 11 de dezembro de 1876 e 6 de janeiro de 1877.

Este artigo busca analisar de modo interdisciplinar, entre a historiografia e a literatura, esse diário de viagem de Dom Pedro II ao Egito em interface com os jornais arquivados na Hemeroteca Digital da Biblioteca Nacional: o "Diário do Maranhão" e o "Diário do Rio de Janeiro" entre 1876 e 1877. O intuito é compreender como era a abordagem da imprensa brasileira sobre o Egito no momento da segunda viagem do imperador e a leitura que Dom Pedro II fazia a respeito das terras egípcias.

Serão comparadas as informações obtidas dos jornais com os diários de viagem de Dom Pedro II e "as manifestações da escrita de si", técnica de análise sugerida por Michel Foucault em 1983 para refletir sobre a experiência individual no diário e para compreender a relação do Egito com o Brasil nos anos de 1870. O recorte aqui apresentado é composto pelos dois jornais no período em que ocorreu a segunda viagem do imperador, entre o final de 1876 e o início de 1877. A análise permite compreender como os brasileiros percebiam o Egito a partir da imprensa e em que medida a viagem do imperador interferiu nessa percepção. A metodologia de pesquisa foi a busca da palavra "Egypto" no sistema de busca da Biblioteca Nacional, e os dois jornais que mais ofereceram referências foram o "Diário do Maranhão" e o "Diário do Rio de Janeiro". O primeiro apresenta mais menções porque há anúncios de produtos e serviços na "Rua do Egito", arruamento no centro da cidade de São Luís. Ambos são publicados todos os dias, com exceção das segundas-feiras.

\section{O imaginário do Egito no "Diário do Maranhão" e o "Diário do Rio de Janeiro" (1876-1877)}

Nos dois anos analisados, entre os meses de março de 1876 e agosto de 1877, contabilizamos 25 aparições do termo Egypto no "Diário do Maranhão", referente ao país, e, no "Diário do Rio de Janeiro", 102 menções ao país. As notícias 
foram divididas em grupos temáticos para possibilitar a compreensão quantitativa das matérias.

O tema "As viagens" $(9,5 \%)$ se refere às notícias sobre viagens ao Egito. Aquelas específicas "a viagem de Dom Pedro II" aparecem em $5,5 \%$ dos casos. O "Canal de Suez" (6,3\%), o "transporte" (2,4\%), a "economia no Egito" (14,9\%) e a "questão do Oriente" $(15,7 \%)$ foram organizados em um conjunto. As "notas" $(16,4 \%)$ são compostas por referências aleatórias e sem contexto específico e as "passagens bíblicas" (6,3\%) também não se referem ao Egito em si, mas utilizam o nome e a história do país para abordar outros assuntos, como questões políticas e religiosas brasileiras, etc. A "escravidão" (1,7\%), apesar de pouco mencionada, são duas matérias sobre o sistema escravista no Egito do XIX. O "Egito Antigo" (5,5\%) é formado por textos informativos sobre história ou arqueologia da antiguidade egípcia. As "exposições internacionais" (3,2\%) são três, uma em Paris, em 1878, e as outras duas nos Estados Unidos em 1876 e 1877. A "produção agrícola egípcia" $(7,8 \%)$ é composta por matérias sobre os números das exportações egípcias, especialmente, de cana de açúcar e algodão, produtos concorrentes dos agricultores brasileiros. $\mathrm{O}$ item denominado "Cultura e Educação" $(2,4 \%)$ reúne informações sobre a ópera Aida, encomendada pelo quediva Ismail, e sobre o sistema educacional egípcio. Por fim, o termo "higiene e saúde" (6,3\%) são comentários referentes a doenças no Egito.

A soma das abordagens em torno da economia e da política nacional e internacional egípcia, composta pelos termos "Canal de Suez", "Transporte", "Economia do Egito", "Questão do Oriente" e "Produção agrícola egípcia", chega a $47,1 \%$ das referências. Já a soma das "viagens", tema que estimulou essa pesquisa, confere $15 \%$ das menções, indicando que há uma predisposição a noticiar viagens ao Egito, em geral, e particularmente a ida de Dom Pedro II ao país. As notas e passagens bíblicas somadas contabilizam $22,7 \%$, o que sugere a utilização do Egito para exemplificar situações ou apenas como uma chamada pitoresca nas seções de variedades ou notas. Os temas elencados foram agrupados em blocos para serem analisados de forma mais ampla e conceitual.

Os jornais estudados sugerem a existência de um conjunto imagético acerca do Egito naqueles anos. A "história do imaginário" é um conceito desenvolvido por Jacques Le Goff (1985), da Escola dos Annales na França, que tentou compreender como a Europa medieval pensava sobre si mesma. O recurso, pode ser apropriado para pensar como o Brasil percebia o Egito no século XIX. 
Nos jornais brasileiros, as notícias chegavam de correspondentes na Europa, especialmente, Londres e Lisboa, e vinham com olhar eurocêntrico. Eram, em geral, publicadas na seção "Europa" ou "Exterior", e quando envolviam as disputas territoriais e conflitos entre ingleses, franceses, russos, egípcios e turcos, recebiam o título "Questão do Oriente". A visão é uma reprodução da leitura eurocêntrica do oriente e a atuação dos europeus deve civilizar os povos árabes como a "Inglaterra civilizada e civilizadora realizou no Egito" (DIÁRIO DO RIO DE JANEIRO, 1876).

As matérias sobre o Canal de Suez se referem ao processo de aquisição inglesa das ações do quediva Ismail, algumas apresentam um histórico da construção, inauguração e uma exaltação do engenheiro Ferdinand Lesseps, responsável pelo projeto ${ }^{3}$. O canal é sempre mencionado como uma obra extraordinária europeia, apesar de sua originalidade ser egípcia, e a manobra inglesa da compra das ações como uma façanha de mestre que integrava os britânicos no comércio com o oriente.

Em um exemplar de fevereiro de 1870, um engenheiro brasileiro, Sr. Marcos Antônio de Macedo, narra sua experiência na inauguração do canal em terras egípcias 4 . Ele descreve a entrada dos barcos no canal e as características da obra, além de compartilhar com os brasileiros sua vivência de subir o rio Nilo do Cairo até Aswan e visitar os monumentos de Filé, Tebas, Abidos e Mênfis. Foi ao Egito para conhecer a engenhosidade da obra de Suez, mas seu depoimento tem um caráter de identificação com o espaço. Chama o deserto de "a ingrata natureza desse país", que ele contemplou do alto do mastro do navio, assustado (DIÁRIO DO RIO DE JANEIRO, 1870). Apesar da comparação, peculiar ao viajante, ele manifesta admiração pela cultura egípcia. $O$ autor era do sertão nordestino

3 A ideia de um canal que conectasse o Mar Vermelho ao rio Nilo remonta a XII Dinastia, quando o Faraó Sesóstris III construiu essa passagem. Em 600 a.C, Necho II tentou reabrir o canal, mas não chegou a finalizar o projeto. Já no século XIX, antes de Lesseps, o pensador e político egípcio Ali Pasha Mubarak escreveu um projeto para a realização de uma obra semelhante ao Canal de Suez, no livro Al-Khitat al-Tawfiqiyya al-Jadid, arquivado na Casa de Documentação e Arquivo Nacional Egípcio, no Cairo.

4 Marcos Antônio de Macedo era natural de Jaicós/PI. Foi Presidente da Província do Piauí nos anos de 1847 e 1848. Elaborou o "Mappa topographico da comarca do Crato província do Ceará" em 1846 e sugeriu nele a criação de um canal saindo do rio São Francisco para o rio Jaguaribe, passando pelo riacho dos Porcos e pelo rio Salgado para amenizar o problema da seca na região (CORTEZ, 2016). 
piauiense onde há áreas arenosas muito secas que causavam migrações populacionais, fome e pobreza. Seu relato remete à leitura de Deleuze sobre a escrita de si que evoca involuntariamente o inconsciente subjetivo do contexto natural e histórico do indivíduo.

As notícias "notas" e "passagens bíblicas" somaram 22,7\% das reportagens. Aqui estão inseridas citações do livro sagrado cristão sobre as pragas ou as cebolas do Egito em um jogo de palavras para criticar a situação política e econômica do Império brasileiro, como a Lei de Ventre Livre, sancionada pela princesa Isabel durante a primeira viagem de Dom Pedro II ao Egito (DEL PRIORE, 2013) e o embate entre os padres, a maçonaria, o Estado e a Igreja, que ocorreu durante a segunda viagem (SANTIROCCHI, 2015). A partir de um pensamento foucaultiano sobre a Ordem do discurso, a narrativa não tem relação em si com o Egito, apenas o referencia, porque o eu narrador utiliza um imaginário sobre o país africano para projetar nele suas críticas ao Brasil.

O teor dessas matérias sugere que o brasileiro dos oitocentos tinha um imaginário acerca do Egito que remetia aos textos religiosos, como a presença de Moisés, a fuga de Nossa Senhora, ou as vidas dos santos, e às descobertas arqueológicas do Egito Antigo, e nesse último, são as maravilhas e grandiosidades dos monumentos egípcios que são exaltados e utilizados para comparar com inúmeros outros objetos ou eventos. Porém, a representação do Egito na mentalidade brasileira do século XIX ainda não está completamente envolvida pelo conceito de "orientalismo" de Edward Said. "O Oriente era quase uma invenção europeia, e fora desde a antiguidade um lugar de romance, de seres exóticos, de memórias e paisagens obsessivas, de experiências notáveis" (SAID, 1990, p. 13). Apesar de já haver uma leitura exótica acerca da região, ela ainda está associada à doutrina cristã, exaltada pelo catolicismo, e pelas descobertas das edificações antigas. Ainda não é perceptível a reprodução de um sentido de superioridade constituído pelos países europeus sobre o oriente. $O$ oriente egípcio é misterioso nesse imaginário brasileiro, mas não é inferior. Pelo contrário, faz parte do cotidiano e é utilizado a todo o momento para fazer comparações com episódios ou questões da política imperial.

Das notícias identificadas, encontramos algumas já de caráter eurocentrista e orientalistas em termos de Edward Said. Elas reproduzem o sentido de um oriente que precisa ser definido pelos europeus para se distanciar da Europa, mas isso não está inteiramente internalizado entre os viajantes brasileiros, como o enge- 
nheiro Marcos Macedo e o próprio Dom Pedro II. Essas matérias sobre as questões econômicas e políticas, em geral, produzidas na Europa, são contundentes e apresentam sempre a solução da crise egípcia nas mãos da Europa, França e Inglaterra, que tão bem sabem lidar com as demandas do oriente, "inferior e não civilizado". Quando as reportagens reproduziam os textos vindos de fora, apresentavam esse viés, mas naquelas escritas por brasileiros, isso se tornava menos efetivo. $O$ uso desse recurso eurocêntrico para o Brasil parece desalinhado com o espaço ocupado pelo próprio país na construção desse conceito, já que o império brasileiro também era descrito por viajantes como o espaço do primitivo e do exótico. O mesmo foi feito pelos europeus acerca do Egito e reproduzir a proposta europeia é também corroborar com a mesma interpretação do Brasil, causando, assim, um incômodo entre a imposição da matriz europeia e a identidade brasileira. A representatividade do outro na redação brasileira é diferente da europeia. Há mais curiosidade e menos certezas na observação e isso abre o espaço para o interesse pelo outro. Essa leitura brasileira vai mudando e adquirindo a influência do conceito de orientalismo em formação no XIX, para começar a modificar a absorção do outro. Em contraposição a essa proposta eurocêntrica, o uso das referências egípcias para criticar a monarquia aproxima as duas terras ao invés de afastá-las, porque faz referência às características da primeira para ironizar os problemas políticos e econômicos brasileiros.

Os anos de 1870 foram conflituosos e os grupos políticos e intelectuais se reordenavam para construírem um ideal de nação brasileira. Interesses distintos disputavam esse espaço e doutrinas econômicas e políticas se misturavam. (CARVALHO, 2007; SCHWARCZ, 1998). Em meio a isso, é possível identificar uma mudança no eixo de influência internacional que começa a sair das mãos de franceses e ingleses e para se direcionar aos Estados Unidos e seu novo poderio em construção. Dom Pedro II representava o eixo europeu, um símbolo de decadência em relação à república, ideal que estava sendo adotado pela geração de 1870 (ALONSO, 2002). Nesse sentido, há um diálogo entre o ideal de nação oitocentista e a política interna brasileira, que é exposto nos jornais a partir do uso irônico de alegorias egípcias para criticar a política imperial e no diário do próprio imperador que, apesar de tentar se evadir da posição de imperador durante sua viagem, também corrobora com a construção de um ideal de nação brasileira. 


\section{Mapeamento afetivo do Diário de Pedro de Alcântara}

Nesta parte vamos rastrear o mapa afetivo da viagem de Dom Pedro II. Por "mapeamento afetivo" entendemos a representação da memória sensível e empática que estabelece o sujeito com o espaço e o outro (SIMMEL, 1903). A partir da análise do diário do monarca, o mapeamento afetivo pode revelar também $a$ escrita de si de Pedro de Alcântara. (DELEUZE, 1980; FOUCAULT, 1983).

Seguindo o conceito de identidade narrativa de Philippe Lejeune (2013), Dom Pedro II estabelecia essa construção identitária ao adotar o nome de Pedro de Alcântara quando entrava no navio para suas viagens ao exterior, esse era o nome pelo qual o imperador gostava de ser chamado em suas viagens. Na sua primeira experiência no Egito, em 1871, esteve no Cairo onde visitou a mesquita de Mohamed Ali, a cidadela de Saladino, as colinas de Mokattam, as pirâmides, a Esfinge, o Palácio de Giza, que foi demolido pelo diretor britânico em 1902 para construir o Zoológico de Giza, a ilha de Zamalek e o Museu de Bulak, hoje Museu Egípcio. O Cairo que ele conheceu era uma cidade muito menor que a dos dias de hoje e era distante da cidadela e das pirâmides. Pedro de Alcântara foi à antiga Mênfis e no caminho comentou com seu olhar delicado, "Mênfis é areia ornada de tamareiras", e em seguida descreve sua chegada a necrópole Sacará: "la de burrinho alongando meus olhos muito e muito além do deserto, bem o sabe Você e dei comigo nas pirâmides de Sakamah". Pedro de Alcântara faz uma interlocução com a Condessa de Barral nesse trecho e o deserto é uma referência ao sentimento dele pela amante/amiga e, associado a isso, há a experiência sensorial do encontro com o monumento. $\mathrm{O}$ conhecimento era o que movia o indivíduo Pedro e estar no Egito escrevendo para sua amada, cúmplice no saber e no amor, era reunir o intelecto ao sentimento, a erudição à memória do romance com D. Luísa Barral (DEL PRIORE, 2008). Nessa primeira viagem, Pedro de Alcântara explorou os monumentos em torno da capital e se deliciou com a experiência cultural em todos os níveis: o povo, os costumes, as ruínas do Egito Antigo e a paisagem e compreendeu a forte relação entre os egípcios dos oitocentos e seu território.

Sua segunda viagem, em 1876, durou mais tempo e ele pôde explorar os templos e tumbas no Alto Egito, seguindo até ao sul de Wadi Halfa, hoje no Sudão. Pedro de Alcântara subiu o Nilo de barco a vapor partindo do porto de Gizeh, em 
Guizé. Enquanto o vapor seguia o curso do rio, ele observava alguns monumentos e vilarejos e comentava, em seu diário, o que via do barco.

Encantou-se com o templo de Luxor. Havia muitas casas ao redor do santuário e parte dele ainda estava encoberto pelas areias. Hoje, completamente escavado, é possível identificar uma das edificações antigas que foram erguidas sob as areias que o cobriam, uma bela mesquita do XVIII em estilo medieval, chamada Abu el-Haggag. Ele também contemplou Karnak por dois dias e ainda assim não foi o suficiente para apreender os inúmeros detalhes do gigantesco templo. Em 1876, ele ainda não havia sido escavado e restaurado e muitas de suas peças estavam espalhadas pelo chão. Algumas salas, hoje recompostas, estavam em ruínas, como a sala do santuário de onde se acredita que era exposta uma estátua de ouro que recebia e refletia a luz do sol na câmara escura de granito preto. São vastos salões com desenhos e hieróglifos em suas colunas, nas paredes e no teto, quando este ainda está preservado. São cenas de guerra, de apresentação de oferendas, de rituais de celebração, etc. Há obeliscos, esfinges e estátuas no entorno da construção principal, templos ao redor e uma avenida de esfinges que liga a Luxor e que hoje está sendo escavada para ser incorporada ao sítio e aberta à visita. "Tudo em Karnak observei com a máxima atenção", dizia Pedro de Alcântara que encantado afirmou, em concordância com o egiptólogo francês Mariette, "Nunca se vê Karnak o suficiente" (PEDRO II, 1876).

Seguiu para Aswan. Ali relata o encontro do Egito com a África subsaariana e retrata a mistura de povos em meio ao mercado e à exposição de produtos das mais variadas origens. A paisagem dessa região se modificou muito desde a construção das represas, a primeira em 1902, e a grande represa em 1970, que deu origem ao enorme Lago Nasser. Visitou a ilha Elefantina, a ilha de Philae e conheceu as cataratas. Os templos de Ísis que ele viu foram retirados de seu lugar original para serem recolocados em uma ilha mais alta com o intuito de não serem invadidos pelas águas. Descreve com carinho as ruínas e transcreve alguns dizeres. Menciona Kalabshe como o segundo templo mais importante da Núbia, sendo precedido por Abu Simbel. É dedicado ao deus Mandulis que é representado por um pássaro com cabeça humana. Sua visita em 1876 encontrou- o em mal estado, com escombros no pátio entre a fachada e a porta de entrada. Hoje, a ilha, onde está Kalabshe, guarda outros três templos: Beit el-Wali, Gerf Hussein e o Kiosko de Kertassi. Pedro de Alcântara conheceu esses templos em seus locais originais, mas nos anos de 1960, eles foram restaurados e transporta- 
dos para uma porção de terra mais alta para que não ficassem submersos pelas águas do lago. Ele descreve Beit el-Wali como um templo escavado na rocha e cuja entrada mostra cenas de guerra, ainda visíveis no edifício restaurado. Gerf Hussein, também denominado Per Ptah, ficava em uma ilha que demandava um bote para ser atingida. O templo apresentava na entrada uma escada ladeada com estátuas que Pedro de Alcântara encontrou arruinadas. Visitou Dendur que hoje está no Metropolitan Museum of Art, em Nova York, doado em contrapartida aos serviços prestados na retirada dos monumentos da área de inundação da represa.

No dia seguinte, visitou Dakkah, um templo do período ptolomaico com inscrições em alto relevo. Em 1876, ele ficava em frente à aldeia de Kabban, hoje submersa. Ao lado dele, hoje está Maharraqah, que Pedro de Alcântara deu pouca importância. Data do período romano e é dedicado a Ísis. Encontrava-se muito arruinado no século XIX, mas foi restaurado no século XX. Ele supôs a existência de uma escadaria, estava certo e ela leva ao topo do pilono. Atualmente encontra-se fechada para visitantes.

Em Sebouah, observou as ruínas e comentou que estavam enterradas nas areias do Saara. Mencionou a presença de duas estátuas na frente do templo, sugerindo que elas eram dezesseis. O templo de Sebouah foi restaurado, suas estátuas do caminho até a fachada foram escavadas, confirmando as suspeitas de Pedro de Alcântara. Conheceu o templo de Amada, dedicado a Amon-Ra, e encontrou-o quase soterrado. Encantou-se com a cena que descreve "Vê-se uma imagem de mulher abraçando uma figura masculina, com os lábios quase se tocando e cuja boca expressa grande doçura" (PEDRO II, 1876). De lá, seguiu para Derr, em cujas paredes analisa as "cenas de batalhas famosas" e comenta a complexidade de diferenciar os deuses egípcios.

Em Abu Simbel, santuário composto por dois grandes templos, um menor dedicado a Hathor, personificada em Nefertari, e outro maior a Ramsés II, Amon, Rá e Ptah, Pedro de Alcântara se esforçou para desenhar as estátuas colossais de Ramsés II, na fachada do templo maior, observando "a expressão dos olhos e da boca" (PEDRO II, 1876). Observou as inscrições datadas dos oitocentos de viajantes que estiveram ali e deixaram sua marca. A cabeça da segunda estátua colossal já estava caída ao chão em 1876, o que foi mantido pela UNESCO no transporte do templo. Atualmente, ele fica muito acima de onde estava, preser- 
vado das águas do Lago Nasser. Em Abu Simbel, Pedro de Alcântara desabafa: "Viagem surpreendente!"

O rio Nilo está presente em todas as descrições de Pedro de Alcântara. É seu encontro com o céu e a terra que ele observa e salienta todos os dias entre a descrição de um templo e outro. $O$ nascente e o poente em harmonia com o rio e a sua moldura árida foram alvo das mais diversas declarações do viajante brasileiro. As cores, as águas, as pedras, a cultura antiga e a oitocentista vivida em torno do Nilo foram evidenciadas em sua viagem. A delicadeza e a humildade de Pedro de Alcântara para com o Egito e a sua exuberância chama a atenção em sua escrita. Ele percorre as águas do Nilo em busca de um passado colossal e se encontra enquanto indivíduo e cientista. É nessa leitura sutil do homem que queria esquecer temporariamente sua responsabilidade de comandar um país e na sua escrita carinhosa para a mulher que amava que Pedro de Alcântara tece um Egito humano. Ele tenta se afirmar como um pesquisador e intelectual, em detrimento do imperador, função que recebeu sem questionar. Mas é o Egito que proporciona a Pedro de Alcântara a sua válvula de escape para se manifestar enquanto homem, constituindo-se, assim, um lugar de potência.

A viagem às terras egípcias e a redação do diário para sua amante, a Condessa de Barral, possibilitaram ao imperador a comparação entre a Europa, os Estados Unidos, o Egito e o Brasil. A leitura orientalista, ainda não adotada completamente pelo monarca brasileiro, é passível de identificação em sua "escrita de si" e observação por meio da egiptologia que surgiu oficialmente em 1822 com a decifração dos hieróglifos, por Jean-François Champollion (1790-1832). Todos esses acontecimentos construíram o imaginário de muitos intelectuais dos séculos XIX e XX sobre o Antigo Egito. Dom Pedro II é um desses homens que se interessaram pelos monumentos egípcios. Ele acompanhou a construção da disciplina da Egiptologia Moderna. Seu pai já se interessava pelo Egito Antigo e muitas obras e objetos sobre o assunto foram adquiridas por eles para o acervo particular dos monarcas ${ }^{5}$ e da própria Biblioteca Nacional. Imbuído dessa curiosidade que se desenvolveu junto ao conceito de oriente, ele faz uma leitura muito própria do Egito e sem se deixar levar completamente pelo pensamento de superioridade europeia. Fascinado com a língua árabe, os hieróglifos e os

5 As peças compradas por Dom Pedro I compunham o acervo do Museu Nacional atingido por um incêndio recentemente. 
monumentos, faz sua segunda viagem para conhecer a Núbia e seus templos. Ele não parece compartilhar desse imaginário exposto pelas notícias vindas da Europa nos jornais brasileiros. (CÂMARA, 2005)

Pedro de Alcântara vislumbra a cidade do Cairo em sua primeira visita e fica fascinado com todas as suas peculiaridades. Queria descrever tudo o que alcançava com seu olhar de cientista, observador, curioso e aberto ao novo. Seguindo a concepção de George Simmel sobre a relação afetiva do sujeito narrador com os lugares, Dom Pedro II interagia com as cidades egípcias de modos distintos e ia formando certa hierarquização dos sentimentos ao mover-se entre as variadas realidades urbanas.

Em sua segunda viagem, organizada pela agência de viagens de Thomas Cook $^{6}$, está muito interessado em visitar os monumentos antigos e, por isso, se direciona ao sul do Cairo e quase não menciona as cidades que já havia visitado. Suas descrições são positivas e analíticas acerca do que vê: "Notei hoje quanto o Nilo carregou grande extensão da margem direita, terreno plantado de belas tamareiras. Não há pôr-de-sol em que os matizes não sejam diferentes e sempre encantadores" (PEDRO II, 1876). As árvores descritas pelo nobre viajante são belas, o pôr do sol colorido e cativante. A natureza é inspiradora para ele e a viagem encantadora: "Encanta-me esta viagem".

Pedro de Alcântara está interessado no Egito Antigo, mas vê o Egito moderno, vê o ser humano, contempla e não julga. Associa as mulheres egípcias que vê à deusa Ísis. Para Pedro de Alcântara, elas são belas e exalam perfumes, mesmo quando não pode expressar essa opinião, como é o caso das dançarinas que descreve.

Os homens que retrata são fortes. Na Núbia comentou: "Meu guia era um belo núbio que trazia seu punhal atado ao braço esquerdo por um bracelete. $\mathrm{E}$ próximo a Luxor, assisti a uma cena tocante: um homem idoso acompanhado por um rapaz e um menino chorava ruidosamente à porta de sua cabana. Acabavam de ver morrer a mulher e mãe" (PEDRO II, 1976). Pedro de Alcântara se reconheceu no sofrimento da família, lembrando que ele próprio perdeu a mãe

6 Depois da nossa apresentação dos resultados da atual pesquisa na Universidade de Aswan em 21 de fevereiro de 2018, a empresa Thomas Cook assina no dia 2 de abril de 2018 acordo com o governo egípcio e o sudanês para ressuscitar o passeio por seu Cruzeiro Dahbia, mesmo nome do barco usado por Dom Pedro II, no percurso do Rio Nilo entre Wadi Halfa e Aswan. 
e o pai muito cedo e em 1871 havia perdido uma filha. Durante sua viagem, ele se identificou com a população local, não os via como inferiores, mas diferentes e iguais.

O diário de Dom Pedro II é uma "escrita de si" que acontece com o propósito de trocar conversas íntimas com a Condessa de Barral, mas também é um desabafo e um momento em que Pedro de Alcântara podia ser autêntico e não precisava ser o imperador do Brasil. Seu texto é um relato de viagem e, nesse sentido, uma redação que se pretende descritiva do outro, os egípcios, e para outro, a Condessa de Barral, mas é também uma autorreflexão (TODOROV, 2006). Em seu texto, é Pedro de Alcântara que narra as experiências de viagem e não o homem público, o imperador Dom Pedro II. É sua identidade narrativa que expressa suas intimidades e observações, suas convivências com o outro. E nesse sentido, a empatia de Pedro de Alcântara para com os egípcios, suas paisagens e sua história é visível. Ali ele se estabelece enquanto homem de letras, o Egito o fascina e o chama para o estudo e o conhecimento. Sua interlocutora é a Condessa de Barral, mulher pela qual ele era apaixonado e viveu um romance de muitos anos. A experiência da viagem que ele retrata é uma forma de estar com a amante cotidianamente. Cada impressão que ele expõe é uma escolha daquilo que quer revelar, são revelações de sua identidade, de parte de seu íntimo e de suas relações com o outro.

Semelhantes aos Grand Tours da elite europeia dos séculos XVIII e XIX cujo objetivo era a aprendizagem a partir da experiência, as suas viagens tinham um caráter educativo, mas também científico e turístico (COSTA, 2009). Nesse caso, ele se comportava como um dos muitos viajantes naturalistas que estiveram no Brasil no século XIX, porém é mais autêntico no contato com o egípcio oitocentista e com o Egito Antigo. É cuidadoso na descrição das pessoas, dos monumentos e das paisagens. Expôs uma visão cosmopolita e humanista num momento de crise política em que vivia o Brasil e a monarquia. Enquanto caminha pelas areias do deserto, em 1871, a princesa Isabel sancionava a Lei de Ventre Livre, e em 1876, discutira a separação entre a igreja e o Estado. Como viajante, olha o outro e, mesmo que se sinta superior pela nobreza e educação europeia, não quer deixar isso transparecer. Ele é o Pedro de Alcântara e não o imperador Dom Pedro II. Ele vê o outro porque quer ser visto. Ele não quer ser o imperador durante suas viagens, quer ser o indivíduo que se deslocou de sua zona de conforto, a corte brasileira, para se entregar às descobertas científicas em uma 
terra distante e encantadora. É o homem e não o monarca. Ao contrário do eurocentrismo que não vê o outro, mas a si mesmo na diferença e com o intuito de identificar o exótico para afirmar as suas características de superioridade, Pedro de Alcântara quer ver o outro para ser visto. Dom Pedro não estava no Egito para ser superior ou exercer nenhum poder que não fosse a sua própria autonomia enquanto indivíduo. Nesse sentido, não vislumbrava os egípcios a partir de um olhar de dominação, pelo contrário, no momento em que experimentava sua liberdade, vislumbrava o outro com ternura e, às vezes, empolgação.

\section{Análise da "escrita de si" de Pedro de Alcântara}

A análise da "escrita de si" é uma técnica sugerida por Michel Foucault em 1983 para refletir sobre a experiência individual nos diários, cartas e cadernetas de anotações. A "escrita de si" é um reflexo do que está dito e do que não está. Os autores, em geral, escrevem sobre si mesmos numa tentativa de expressar o que têm de melhor e afastar o pior. Isso é possível de ser estudado nos jornais "Diário do Maranhão" e "Diário do Rio de Janeiro" e no diário pessoal de Pedro de Alcântara. O jornalista das reportagens sobre o Egito nos anos de 1870 escreve sobre o Egito, mas também sobre si mesmo a partir das suas escolhas para a ordem do texto, as palavras e os temas. Em um diário ou uma autobiografia, isso é muito mais transparente. Já nos periódicos, essa escrita está subentendida, escondida. As notícias de jornais e o diário de Pedro de Alcântara refletem a "escrita de si" de seus autores e essa escrita retrata o imaginário que esses escritores tinham sobre o Egito. Nesse sentido, nesses textos as "escritas de si" do imperador e dos jornalistas possibilitam compreender a relação do Egito com o Brasil nos anos de 1870.

O diário de Pedro de Alcântara apresenta os pensamentos, os sentimentos e o imaginário do imperador em torno do Egito. Ele escreve para sua amada e ressalta o que entende como mais importante e recorta o que não deseja transparecer. Como é o indivíduo que escreve, ele produz atitudes afetivas perante esses lugares. A partir da escolha dos lugares que referencia, estabelece elo afetivo com eles (YI FU TUAN, 1974). O brasileiro que fala do Egito para falar de si está lançando mão de um imaginário comum para afirmar as insatisfações com a sociedade imperial e suas questões econômicas, políticas e religiosas. Já o impe- 
rador expressa seu ideal de nação quando compara o que conhece no Brasil com o que vê no Egito. O imaginário disposto na "escrita de si" de Pedro de Alcântara é a expressão de um conjunto cultural brasileiro sobre o Egito e, também, sobre o próprio Brasil. Pedro de Alcântara fala de si como brasileiro em contraposição ao outro, os egípcios, relacionando os dois países em sua memória afetiva das terras egípcias. Nessas percepções, nos deparamos com o que Simmel explica da vacilação do narrador entre olhar dentro e olhar fora da realidade que testemunhava as relações sociais de poder da época.

\section{Considerações finais}

O Egito é um país milenar e sua história inspira os homens desde a antiguidade. Nos séculos XVIII e XIX, seus monumentos foram estudados por europeus que estavam maravilhados com a história egípcia antiga, mas que inferiorizavam os habitantes contemporâneos. A Egiptologia é fruto desse contexto orientalista e reflete essa ideologia.

O monarca brasileiro, quando esteve no Egito, produziu um diário relatando a sua experiência de viagem e seus pensamentos sobre o país. Enquanto isso, no Brasil, a imprensa noticiava os problemas nacionais e internacionais e dava um espaço peculiar para o Egito. Os jornais, "Diário do Maranhão" e "Diário do Rio de Janeiro", lançavam mão de alegorias egípcias para escrever sobre a política nacional. Assim, a partir articulação entre os conceitos de "imaginário", "mapa afetivo" e "escrita de si" analisamos o Egito numa interface entre o Diário de Dom Pedro Il e os jornais "Diário de Maranhão" e no "Diário do Rio de Janeiro" entre 1876 e 1877.

Dialogar com os jornais e o diário do imperador possibilita a análise do imaginário do Egito no século XIX. A representação desse imaginário e o "mapeamento afetivo" e a "escrita de si" do monarca demonstram os processos da construção da identidade brasileira e do indivíduo Pedro de Alcântara, encarnados no momento do encontro com o outro. Esse outro, que pode ser o Egito ou a mulher-amante, está disposto nas narrativas jornalísticas ou íntimas como tema dos textos ou interlocutores deles.

Historicamente, o momento estudado é um período de crise política e de transformações no Brasil e no mundo. Estas mudanças conduzem Dom Pedro II a 
buscar o caminho da viagem e a escrita do diário de campo como uma forma de renovar-se ante o encontro com o outro. Ao mesmo tempo, ele se esforça num encontro consigo mesmo na busca de uma identidade de si enquanto Pedro de Alcântara e de uma identidade nacional brasileira que resiste às avalanches das modificações da virada do século. $\mathrm{Na}$ análise, o outro também poderia ser considerado como as duas mulheres que rodeiam a vida do imperador, a esposa, Dona Thereza Cristina, e a amante/amiga, Luíza de Barral. Elas eram, de certa maneira, no caso da experiência da viagem e do diário, companheiras e interlocutoras na produção de sentidos sociais nesse período finissecular.

Discursivamente, a interpretação dos "mapas afetivos" e da "escrita de si" é necessária para a construção dos sentidos sociais no discurso da imprensa e no literário do "Diário". A inter-relação entre os três conceitos pilares (imaginário, escrita de si e mapa afetivo) da pesquisa nas fontes primárias levou à identificação do processo de encontro histórico entre as duas culturas sul/sul num cenário geopolítico imperialista norte/sul. São jornais e um diário de viagem brasileiros que abordam o Egito com o intuito de afirmarem a própria identidade de país e indivíduo, mas sem, contudo, empreenderem um olhar de supremacia. Esse contato intercultural ocorre em contraposição a um momento histórico em que os convívios entre culturas marcadas pela dominação não aconteciam. O Brasil e o Egito sofriam nessa conjuntura as imposições da Europa e dos Estados Unidos e esse contato é uma brecha que dá voz à autonomia de brasileiros e egípcios, abafada pelo imperialismo.

Essas interpretações interdisciplinares (história e imprensa) e interculturais (Brasil/Egito) podem abrir caminhos de diálogo e de intercompreensão no século XXI. Uma vez apresentados esses mecanismos da produção jornalística e literária, a pesquisa inspirou a intermediação entre o Egito e o Sudão, como ponte de encontros entre árabes e africanos e entre árabes e brasileiros. $O$ estudo dessas memórias culturais afetivas que transpõem as habituais relações norte/sul, compostas por uma hegemonia geopolítica mundial, podem incentivar as mobilidades entre o Brasil e o Egito e construir novos laços fundamentados na proximidade entre os países do hemisfério sul. Nesse sentido, este estudo comparado entre os dois países conduz ao questionamento das relações hegemônicas norte/sul para abrir espaço, em termos de Boaventura Souza de Santos (2010), às novas epistemologias e suas respectivas enunciações, fruto do contato entre as identidades sul/sul, cuja cooperação Dom Pedro II foi o precursor. 


\section{Referências bibliográficas}

ALONSO, Angela. Ideias em movimento: a geração de 1870 na crise no Brasil-Império. São Paulo: Paz e Terra, 2002.

BIBLIOTECA NACIONAL. Fotografias: "Coleção D. Thereza Chistina Maria". Rio de Janeiro: A Biblioteca, 1987.

CARVALHO, José Murilo de. D. Pedro II. São Paulo: Companhia das Letras, 2007. CORTEZ, Ana Isabel Parente e IRFFI, Ana Sara Parente Cortez. Cartografias históricas e modernização do território cearense na segunda metade do século XIX: Primeiros resultados de uma pesquisa. Revista Porto, n. 04, 2016, p. 27-44.

COSTA, Flávia Roberta. Turismo e patrimônio cultural. São Paulo: Editora Senac São Paulo: Edições SESC SP, 2009.

DELEUZE, Gilles; GUATTARI, Félix. Mil Platôs: capitalismo e esquizofrenia. (Original foi publicado em 1980), Tradução de Aurélio Guerra Neto, Célia Pinto Costa. Rio de Janeiro: Ed. 34, 1995. v. 1.

DIÁRIO DO RIO DE JANEIRO. Exterior. Inauguração do Canal de Suez. Rio de Janeiro, ano 53, $\mathrm{n}^{\circ}$ 38, 07 fev. 1870. Biblioteca Nacional. Disponível em <http://bndigital.bn.gov.br/ hemeroteca-digital/>

DIÁRIO DO RIO DE JANEIRO. Diário do Rio de Janeiro. Viagem de suas majestades imperiais. Rio de Janeiro, ano 54, $n^{\circ}$ 346, 17 dez. 1871. Biblioteca Nacional. Disponível em $<$ http://bndigital.bn.gov.br/hemeroteca-digital/>

DIÁRIO DO RIO DE JANEIRO. Europa. Rio de Janeiro, ano 59, n 4, 05 jan. 1876. Biblioteca Nacional. Disponível em <http://bndigital.bn.gov.br/hemeroteca-digital/>

FOUCAULT, Michel. "A escrita de si”, Corps écrit, no. 5: L'autoportrait, fevereiro de 1983, ps. 3-23.

LE GOFF, Jacques. O Imaginário Medieval. Lisboa: Editorial Estampa, 1994 [original: 1985]

LEJEUNE, Philippe. "Da autobiografia ao diário, da Universidade à associação: itinerários de uma pesquisa". Letras de Hoje, Porto Alegre, v. 48, n. 4, p. 537-544, out./dez. 2013. PEDRO II, Dom. Diários. In: BEDIAGA, Begonha (Org.). Diário do Imperador D. Pedro II: 1840-1891. Petrópolis: Museu Imperial, 1999.

PRIORE, Mary Del. Condessa de Barral: a paixão do imperador. Rio de Janeiro: Objetiva, 2008.

PRIORE, Mary Del . O castelo de papel: uma história de Isabel de Bragança, princesa imperial do Brasil, e Gastão de Orléans, conde d'Eu. Rio de Janeiro: Rocco, 2013.

SANTOS, Boaventura de Sousa e MENESES, Maria Paula. (Orgs.) Epistemologias do Sul. São Paulo: Editora Cortez. 2010. 
SIMMEL, George. The Metropolis \& Mental life. New York: Free Press, 1979. (Original publicado em 1903).

SAID. Edward W. Orientalismo: o Oriente como invenção do Ocidente. São Paulo: Companhia das Letras, 1990.

SANTIROCCHI, Ítalo Domingos. Questão de consciência: os ultramontanos no Brasil e o regalismo do Segundo reinado. Belo Horizonte: Fino Traço, 2015.

SCHWARCZ, Lilia Moritz. As barbas do imperador: D. Pedro II, um monarca dos trópicos. São Paulo: Companhia das Letras, 1998.

STRAUCH, Paulo Cesar. Pindorama e o Palácio de Cristal: um olhar sobre a exposição de Londres de 1851. Rio de Janeiro: E-papers Ed., 2008

TIGNOR, Robert L. Egypt: Short History. Princeton: Princeton University, 2011.

TODOROV, Tzvetan. A viagem e seu relato. Rev. Let., São Paulo, v. 46, n 1, p. 231-244, jan/jun. 2006.

UNESCO. História geral da África, VI: África do século XIX à década de 1880, editado por J. F. Ade Ajayi, Brasília: UNESCO, 2010.

YI FU TUAN. Topophilia- A Study of environmental perception, attitudes, and values. New Jersey: Prentice-Hall Inc., Englewood Cliffs,1974. 